\title{
Association of physical fitness with quality of life in community-dwelling older adults aged 80 and over in Poland: a cross- sectional study
}

Ewelina Lepsy', Ewa Radwańska', Grzegorz Żurek², Alina Żurek³, Antonina Kaczorowska', Alina Radajewska ${ }^{4}$ and Anna Kołcz ${ }^{5^{*}}$ (D)

\begin{abstract}
Background: Aging is a progressive and irreversible process that negatively affects the quality of life (QOL). Older adults face difficulties related to worsening health, lowering the level of physical and mental efficiency. We aimed to analyze the associations between physical fitness and QOL in Polish older adults considering sex differences.

Methods: This cross-sectional study was performed from March to August 2015. The sample consisted of 100 community-dwelling adults (67 women, 33 men) with a mean age of $82.94 \pm 2.67$ years. The World Health Organization QOL, Short Form questionnaire (WHOQOL-BREF), and the Fullerton Functional Fitness Test (FFFT) were used. Biometric data, social and environmental situation, nutritional and lifestyle behaviors have been also collected using a questionnaire designed by the authors.

Results: The results obtained in individual domains of WHOWOL-BREF indicate a good level of QOL in all the examined domains. Statistically significant sex differences were obtained in physical $(p=0.01)$, psychological $(p=$ $0.04)$ and environmental $(p=0.02)$ domains in WHOQOL-BREF. It was noted that men perform better in terms of the upper (arm curl, $p<0.001$ ) and lower body strength (chair stand, $p=0.01$ ), aerobic endurance (two-minute step test, $p<0.001$ ), agility and dynamic balance (up and go test, $p<0.001$ ) in FFFT.

Conclusions: Community-dwelling older adults aged 80-93 years in Poland present a good level of QOL, and the higher score was obtained in men. Also, men presented better physical fitness, showed a higher level of independence in daily activities, and assessed better their own QOL than women.
\end{abstract}

Keywords: Quality of life, Physical fitness, Psychosocial factors, Lifestyle

\section{Background}

The reflection on aging should begin with an awareness of the scale of this phenomenon, which affects all aspects of life. Excessive aging is noteworthy, relating to the increase in the proportion of the elderly population,

\footnotetext{
* Correspondence: anna.kolcz@umed.wroc.pl

${ }^{5}$ Laboratory of Ergonomics and Biomedical Monitoring, Wroclaw Medical University, Grunwaldzka 2, 50-355, Wroclaw, Poland

Full list of author information is available at the end of the article
}

a subpopulation of very older people ( 80 years of age and above) [1]. This phenomenon results from two wellknown reasons for the aging of the population - the first one is a decline in the number of births and the second one is a lower mortality rate, as confirmed by the most recent global decomposition analysis [2].

According to current EUROSTAT data [3], the European Union is an agglomeration of more than 500 million people, 19.2\% (approximately 100 million) are older

(c) The Author(s). 2021 Open Access This article is licensed under a Creative Commons Attribution 4.0 International License, which permits use, sharing, adaptation, distribution and reproduction in any medium or format, as long as you give appropriate credit to the original author(s) and the source, provide a link to the Creative Commons licence, and indicate if changes were made. The images or other third party material in this article are included in the article's Creative Commons licence, unless indicated otherwise in a credit line to the material. If material is not included in the article's Creative Commons licence and your intended use is not permitted by statutory regulation or exceeds the permitted use, you will need to obtain permission directly from the copyright holder. To view a copy of this licence, visit http://creativecommons.org/licenses/by/4.0/. The Creative Commons Public Domain Dedication waiver (http://creativecommons.org/publicdomain/zero/1.0/) applies to the data made available in this article, unless otherwise stated in a credit line to the data. 
people. Demographic data predict that the number of people aged 80 and over will double in European countries by 2060. In Germany, Slovakia, Spain, Portugal, and Greece, the percentage will be $13.4-16.1 \%$ of the total population and Poland 12.3\% [4, 5]. The aging population causes dramatic demographic, epidemiological, and anthropological changes, emphasizing active, and healthy aging philosophy [6].

According to the World Health Organization (WHO) [7], planning an exercise training program for older people should consider their goals and aspirations to be more motivated to engage in systematic physical activity. One of the most important factors influencing the health condition of the elderly is physical activity $[8,9]$.

Systematically undertaken physical activity supports the treatment of chronic diseases and enables a healthy, active life without functional barriers [10-12]. Moreover, the reduction of physical activity in older people promotes many chronic diseases, including hypertension, diabetes, obesity, cardiovascular diseases, strokes, and some cancers [13, 14]. Recent studies highlighted that systematic and appropriately dosed physical activity could delay aging processes $[15,16]$. It also allows older people to maintain their physical fitness at a level that enables them to function more independently $[17,18]$. Evidence from observational studies supports the beneficial effects of physical activity on cognition $[19,20]$. However, strong evidence from randomized controlled trials is still lacking, and e.g., in the LIFE study, beneficial effects of physical activity on cognition were only seen in subgroup analyses [21, 22].

As life expectancy is still increasing among the world's population, the main concern is whether the extended time is related to years of healthy life and promotes a high health-related quality of life (HRQOL) until old age [23]. Regular physical activity, which helps to improve physical and mental functions and reverse some of the effects of chronic diseases to maintain the mobility and independence of older people, will become increasingly important [24]. Physical fitness and physical activity play an essential role in the quality of life (QOL) of older adults, especially in those who often have difficulties in everyday activities and psychological and social functioning [25].

Daimiel et al. [26], in their PREDIMED-Plus trial, showed that higher levels of physical activity and physical fitness are strongly associated with a better level of QOL - higher scores in all domains of the SF36-HRQL questionnaire. Polish cross-sectional study by Puciato et al. [27] conducted among over 1000 participants showed that the overall QOL, the perceived health status, and the QOL in the physical, psychological, social, and environmental domains of WHOQOL-BREF were significantly better in people with higher levels of physical activity. Also, Oh et al. [28] investigated the effects of three of the most representative exercises (resistance, flexibility, and walking) on QOL in a population of community-dwelling older adults. They observed that QOL parameters (EuroQOL) such as mobility, self-care, usual activities, pain/discomfort, anxiety/depression were improved.

Numerous studies have been undertaken on QOL and activity in older people $[29,30]$ as well as age-related physical disability [31, 32]. In Poland, it was found that in population of people aged $60-80$, almost $30 \%$ suffer from at least a moderate level of disability and over $10 \%$ experience severe disability [33]. However, the dominant age group studied were people between 60 and 80 years of age. As the number of people aged 80 and over is growing, there is a need to acquire up-to-date knowledge to improve the QOL. For this age group, there is a lack of studies on the impact of involutional processes that consider the level of independence in everyday life, lifestyle, activity, and physical fitness on the assessment of QOL.

The study aimed to analyze the association between physical fitness level with the QOL of Polish older adults. For this purpose, two main research questions were formulated: (1) Are the general QOL and its particular domains (physical, psychological, and social) associated with the level of physical fitness among the studied population? (2) Are there any sex differences in the relationship between physical fitness and QOL among the studied population? It was assumed that higher status of chosen physical, psychological, and social domains is related with better level of physical fitness as well as that men present better physical fitness which is associated with their higher QOL than in women.

\section{Methods \\ Study design and participants}

This cross-sectional study was conducted in southwestern Poland (Opole, Lower Silesia, and Silesia) from March to August 2015. The study consisted of 100 community-dwelling adults (67 women and 33 men) aged 80-93. The STROBE (STrengthening the Reporting of OBservational studies in Epidemiology) guidelines for observational studies were followed.

\section{Qualification criteria}

The criteria for inclusion covered persons who: (1) were aged 80 years and above at the start of the study, (2) did not show any impairment in their ability to respond logically and independently, (3) lived in an independent or shared household, and (4) gave informed and voluntary consent to participate in the study. In turn, the exclusion criteria were: (1) health factors that make it 
impossible to conduct the study, such as consciousness disorders, psychosis, dementia, cognitive disorders, (2) distrust, aversion, and apparent fear of the test subjects towards the test subject's home visit, (3) living in centers providing care for the elderly, and (4) lack of consent to participate in the study.

\section{Data collection}

The study participants were recruited based on eligibility data from rehabilitation facilities in three districts of south-western Poland, and the target population was older individuals aged over 80 years. The survey was conducted individually at the home of the examined person after obtaining voluntary consent. The home visits took place in the morning, when the psychophysical condition of the respondents was the most favorable. Before the study began, the participants were informed about the purpose of the study, and they were instructed on how to answer the questions. During the survey, everyone could obtain additional information in case of any ambiguities. Each survey lasted from 1.5 to $2 \mathrm{~h}$ and was started with a survey-based interview, always in a specific procedure. Subsequently, questions were asked according to an original questionnaire (Appendix 1).

The received answers and statements were noted during the home visit of the interviewers. The survey investigators took part in the training, during which they were familiarized with the objectives of the study, the structure of the questionnaires, and instructions on how to fill them out and how to communicate effectively with the respondents. All participants were informed about the purpose and course of the study and agreed in writing to participate. During the study, we attempted to contact 150 individuals anticipated to participate in the study, of which 123 were successfully contacted. A final sample of 100 individuals was obtained during qualification. Our contact rate of $68.33 \%$ and response rate of $81.30 \%$ are reasonable and consistent with response rates obtained in other population-based studies.

\section{Sample size}

The estimated sample size for a two-sample unpairedmeans test (unpaired t-test) was calculated using Statistica 12 (TIBICO, Inc., USA). For the Student's t-test, the test power for body height was 1.000 , and body mass was 0.997 . The minimum number of samples is $\mathrm{N} 1=\mathrm{N} 2=20$ (for height) and $\mathrm{N} 1=\mathrm{N} 2=25$ for body mass. The alpha level was set at 0.05 , and the power of the test 1-beta at 0.9. It also assumed no correlation of evaluated variables and adopted a 2-sided null hypothesis. Based on the parameters, the estimated sample size has been obtained for a minimum number of patients in both compared groups is $\mathrm{N} 1$ (women) $=\mathrm{N} 2($ men $)=25$ in the study. The final sample size in this research was 100 participants.

\section{Measurements}

The following research tools were used to assess study outcomes: (1) World Health Organization QOL Standardized Questionnaire, Short Form (WHOQOL-BREF) to assess QOL levels, (2) Fullerton Functional Fitness Test (FFFT) to assess physical performance, and (3) original survey questionnaire designed for the purpose of this study including 40 questions on biometric data, anthropometric characteristics, family and environmental situation, nutritional and lifestyle behaviors (Appendix 1).

\section{World Health Organization QOL, short form (WHOQOL- BREF)}

The QOL examination of older adults was performed using the WHOQOL-BREF questionnaire based on the WHOQOL 100; it is designed for subjective QOL assessment [34]. It analyses four primary areas of life: physical, psychological, social, and environmental, as well as overall QOL and self-assessment of health. In the physical field, older adults are assessed: activities of daily living, dependence on medicinal substances and medical aids, energy and fatigue, mobility pain and discomfort, sleep and rest, and work capacity. In the psychological field: bodily image and appearance, negative feelings, positive feelings, self-esteem, spirituality/religion / personal beliefs, thinking, learning, memory, and concentration. In the social field: personal relationships, social support, sexual activity. In the environmental field: financial resources, freedom, physical safety and security, health and social care (accessibility and quality), home environment, opportunities for acquiring new information and skills, participation in and opportunities for recreation/ leisure activities physical environment, (pollution, noise, traffic, climate), and transport [35].

The WHOQOL-BREF questionnaire is used to evaluate the psychometric QOL; on a five-stage scale, the respondent's emotional and physical state is analyzed. The score for particular domains is determined by calculating the arithmetic mean from the positions included in particular domains. The scoring has a positive direction, which means that more points indicate a better QOL [36]. According to Jaracz et al. [37], who described psychometric properties of the Polish WHOQOL-BREF, it was shown a high validity ranged between $0.62-0.76$ for the physical domain, $0.55-0.78$ for the psychological domain, $0.68-0.85$ for the social domain, and $0.58-0.68$ for the environmental domain.

\section{Fullerton functional fitness test (FFFT)}

The FFFT tool, based on the American College of Sport Medicine, was used to assess physical fitness using several medical consultations. It was published by Rikli and Jones [38] and assesses all the physiological properties that are necessary to maintain safe daily activity and 
independence. It is designed to assess the functional performance of older adults, i.e., those over 60 years of age, and consists of six trials to assess the strength of the upper body - arm curl; the strength of the lower body chair stand; flexibility within the upper body - back scratch test; flexibility within the lower body - chair sitand-reach; agility and dynamic balance -8 -ft up and go; aerobic endurance - six-minute walk test or two-min step test.

Instruction and a demonstration preceded the performance of tests. In Polish conditions, the adaptation of units of measurement and weight (e.g., inches, feet, pounds) was used, making it possible to perform tests using commonly available tools. The FFFT is a safe research tool for the elderly and can be used without additional medical examinations. It is easy to perform and requires no special equipment. It is a useful research tool because it allows identifying areas of individual weakness and preparing intervention programs, and comparing the results of individuals of the same age and sex [39]. The FFT represents good reliability and variability ranged between $0.79-0.97$, and the repeatability between $0.80-0.97$ [39]. This measurement tool was also used in the previous studies among polish population by Ignasiak et al. [40], Umiastowska and Kupczyk [41], and Nawrocka et al. [42].

\section{Ethical considerations}

The study protocol was approved by the Bioethics Committee of the Opole Medical School, Poland (permission no. 3/2015). All patients provided informed consent and were informed that they could withdraw from the study at any stage. The study was carried out following the tenets of the Declaration of Helsinki and Good Clinical Practice guidelines.

\section{Statistical analyses}

The results were analyzed using Statistica 12 (TIBICO, Inc., USA). All quantitative variables were tested with the Shapiro-Wilk test to determine the type of distribution. For parameters where there were no grounds for rejecting the normal distribution hypothesis, mean values $(\mathrm{M})$, standard deviation (SD), and coefficient of variation $(v)$ were calculated. For parameters where the normal distribution hypothesis was rejected, median $(\mathrm{Me})$, lower $(\mathrm{Q} 1)$, and upper $(\mathrm{Q} 3)$ quartiles, minimum (min), and maximum (max) were calculated. The significance of differences between the mean values was estimated using the Student's t-test. Differences between the groups were calculated with the Mann-Whitney U test. The Pearson correlation coefficient (for normal distribution) and Spearman's ranked correlation coefficient (for non-normal distribution) were used. In order to assess the relationship between a dependent variable and a collection of independent variables, multiple regression analysis was applied (step regression). In all analyses, the level of $p<0.05$ was assumed to be statistically significant.

\section{Results}

The study group included women $(n=67)$ and men $(n=$ 33 ) aged $80-93$ years. The major group was people living in the countryside $(76 \%)$, in $82 \%$ with primary vocational education. The characteristic of the study group is presented in Table 1.

The first two items of WHOQOL-BREF (overall QOL and general health) were analyzed separately and concerned individual perception of QOL. The mean values of the overall QOL and general health in men were slightly higher than in women. The mean values of individual general health were significantly different (Table 2).

Furthermore, a much better perception of environmental, psychological, and physical functioning was shown in men. In turn, the highest scores in social relations and environmental functioning were observed in women. In both groups, the lowest score was in the physical domain. The evaluation of social relations was almost the same in women and men. The analysis showed statistically significant differences between the mean scores in physical, psychological, and environmental domains (Table 2).

In the FFFT, statistically significant sex differences in the mean values in chair stand, arm curl, two-minute step test, and up and go was shown in favor of men. In the back scratch test, better results were achieved by women; however, not statistically significant (Table 2).

Also, a correlation was shown between the overall QOL and the results of the FFFT in older people (Table 3). The most significant relationships in women were observed between the overall QOL, general health, and all domains of WHOQOL-BREF and the results of the four FFFT tests (chair stand, arm curl, two-minute step test, and up and go). It was observed that the higher the physical fitness, the higher the QOL in women. In the group of men, there were less significant relationships observed. The environmental domain was correlated with the four FFFT tests (chair stand, arm curl, two-minute step test, and sit and reach test). The physical domain was correlated with the results of three FFFT test (up and go, arm curl, chair sit-and-reach) and the psychological domain with the results of two FFFT test (up and go, and 2-min walk) (Table 3).

A correlation was shown between women's age and the results of three FFFT test (chair stand, two-minute step test, and back scratch test). A different perception of the physical domain with age was presented in women than men. The psychological and social domains decrease with age in the group of women and men, but 
Table 1 Characteristics of study participants including sex differences $(n=100)$

\begin{tabular}{|c|c|c|c|c|c|c|c|}
\hline \multirow[t]{2}{*}{ Feature } & \multicolumn{2}{|c|}{ Women $(N=67)$} & \multicolumn{2}{|c|}{ Men $(N=33)$} & \multicolumn{3}{|c|}{ Student's t-test } \\
\hline & $\bar{M}$ & SD & $\bar{M}$ & SD & $\bar{t}$ & $p$ & $1-\beta$ \\
\hline Age [years] & 82.9 & 2.7 & 83.0 & 3.4 & -0.14 & 0.887 & \\
\hline Height [cm] & 157.9 & 5.5 & 170.1 & 4.8 & -10.76 & $<0.001$ & 1.000 \\
\hline Body mass [kg] & 68.5 & 9.9 & 77.4 & 8.3 & -4.43 & $<0.001$ & 0.994 \\
\hline BMI $\left[\mathrm{kg} / \mathrm{m}^{2}\right]$ & 27.46 & 3.85 & 26.77 & 2.77 & 0.92 & 0.358 & \\
\hline
\end{tabular}

Abbreviations: $B M I$ body mass index, $N$ number of participants, $M$ mean, SD standard deviation, $t$ t-quantile, $p$ statistical significance, $1-\beta$ power of the test Notes: *values in bold indicate statistical significance $(p<0.05)$

it shows a stronger tendency in the group of women (Table 4).

In the group of women, the environmental domain was related to the results of two FFFT test (arm curl, and up and go); however, chair stand was associated with the remaining physical, psychological, and social domains. The range values of $\beta$ standardized for four domains in women were from -0.34 to 0.57 . The performance of up and go test was shown a negative correlation (Table 5).

In the group of men, significant correlations were shown with the results of two FFFT test (2-min walk, and chair stand0; however, the results of the two-minute step test were associated significantly with physical and psychological domains. The environmental domain was related to the results of the chair stand test. The range value of $\beta$ standardized for these three domains was from 0.47 to 0.53 . In the men studied, no fitness test was significantly related to the social domain QOL (Table 6).
Mobility endurance, upper and lower body strength, balance, coordination, and speed are associated with the particular domains of QOL among older adults studied.

\section{Discussion}

Our study indicates that community-dwelling older adults aged 80-93 years in Poland present a good level of QOL, which is associated with a good level of physical fitness. However, a higher level of QOL was observed in men. Similarly, men present better physical fitness and physical activity, including mobility endurance, upper and lower body strength, balance, coordination, and speed. Moreover, men show a higher level of independence in daily activities and assess their QOL better than women. It was noted that men had better results in FFFT in terms of the upper (arm curl) and lower body strength (chair stand), aerobic endurance (two-minute step test), agility, and dynamic balance (up and go test). It was also observed that the level of physical fitness of

Table 2 Between sex differences for comparisons in QOL domains and physical fitness parameters

\begin{tabular}{|c|c|c|c|c|c|c|}
\hline \multirow[t]{2}{*}{ Feature } & \multicolumn{2}{|c|}{ Women $(N=67)$} & \multicolumn{2}{|c|}{ Men $(N=33)$} & \multicolumn{2}{|c|}{ Student's t-test } \\
\hline & $M$ & SD & $M$ & SD & $\mathrm{t}$ & $\mathbf{p}^{*}$ \\
\hline Overall QOL [score] & 3.81 & 0.94 & 4.09 & 0.81 & -1.49 & 0.1393 \\
\hline General health [score] & 3.42 & 1.02 & 3.85 & 0.71 & -2.18 & 0.0317 \\
\hline Physical domain [score] & 24.27 & 5.62 & 27.24 & 4.6 & -2.63 & 0.0099 \\
\hline Psychological domain [score] & 22.84 & 4.55 & 24.73 & 3.67 & -2.08 & 0.0404 \\
\hline Social domain [score] & 11.67 & 1.85 & 11.88 & 1.88 & -0.52 & 0.6024 \\
\hline Environmental domain [score] & 31.08 & 4.81 & 33.52 & 4.44 & -2.45 & 0.0162 \\
\hline Chair stand [n] & 7.34 & 3.33 & 9.55 & 4.35 & -2.8 & 0.0061 \\
\hline Arm curl [n] & 9.78 & 3.94 & 12.97 & 4.83 & -3.53 & 0.0006 \\
\hline Two-minute step test [n] & 26.88 & 18.49 & 39.24 & 19.96 & -3.06 & 0.0028 \\
\hline Back scratch test $[\mathrm{cm}]$ & -22.71 & 17.6 & -26.45 & 20.12 & 0.94 & 0.349 \\
\hline Up and go [s] & 19.93 & 12.64 & 12.03 & 4 & 3.49 & 0.0007 \\
\hline \multirow[t]{2}{*}{ Feature } & \multicolumn{2}{|c|}{ Women $(N=67)$} & \multicolumn{2}{|c|}{ Men $(N=33)$} & \multicolumn{2}{|c|}{ Mann-Whitney U test } \\
\hline & Me & Min-Max & Me & Min-Max & z & $p^{*}$ \\
\hline Vertical jump test $[\mathrm{cm}]$ & 0 & $-49-5$ & 0 & $-36-8$ & 0.43 & 0.6873 \\
\hline
\end{tabular}

Abbreviations $N$ number of participants, $Q O L$ quality of life, $M$ mean, $S D$ standard deviation, Me median, Min minimum, Max maximum, $t$ t-quantile, $p$ statistical significance, $z$ z-quantile 
Table 3 Between sex differences for correlations of the QOL domains and physical fitness parameters

\begin{tabular}{|c|c|c|c|c|c|c|c|c|c|c|c|}
\hline & Feature & $\begin{array}{l}\text { Age } \\
\text { [years] }\end{array}$ & $\begin{array}{l}\text { Height } \\
{[\mathrm{cm}]}\end{array}$ & $\begin{array}{l}\text { Body } \\
\text { mass } \\
{[\mathrm{kg}]}\end{array}$ & $\begin{array}{l}\mathrm{BMI} \\
{\left[\mathrm{kg} / \mathrm{m}^{2}\right]}\end{array}$ & $\begin{array}{l}\text { Chair } \\
\text { stand [n] }\end{array}$ & $\begin{array}{l}\text { Arm } \\
\text { curl }[n]\end{array}$ & $\begin{array}{l}\text { Two-minute } \\
\text { step test [n] }\end{array}$ & $\begin{array}{l}\text { Sit and reach } \\
\text { test }[\mathrm{cm}]\end{array}$ & $\begin{array}{l}\text { Back scratch } \\
\text { test }[\mathrm{cm}]\end{array}$ & $\begin{array}{l}\text { Up and } \\
\text { go [s] }\end{array}$ \\
\hline \multirow[t]{6}{*}{$\begin{array}{l}\text { Women } \\
(N=67)\end{array}$} & $\begin{array}{l}\text { Overall QOL } \\
\text { [score] }\end{array}$ & -0.12 & -0.20 & -0.08 & 0.01 & 0.50 & 0.40 & 0.47 & 0.07 & 0.13 & -0.53 \\
\hline & $\begin{array}{l}\text { General health } \\
\text { [score] }\end{array}$ & -0.16 & -0.17 & -0.19 & -0.06 & 0.60 & 0.34 & 0.44 & 0.15 & 0.09 & -0.61 \\
\hline & $\begin{array}{l}\text { Physical } \\
\text { domain }\end{array}$ & -0.26 & -0.13 & -0.02 & 0.08 & 0.56 & 0.39 & 0.37 & 0.19 & 0.08 & -0.58 \\
\hline & $\begin{array}{l}\text { Psychological } \\
\text { domain }\end{array}$ & -0.28 & 0.14 & -0.05 & 0.04 & 0.57 & 0.33 & 0.48 & 0.12 & 0.12 & -0.56 \\
\hline & Social domain & -0.16 & -0.14 & 0.03 & 0.09 & 0.41 & 0.17 & 0.38 & 0.12 & 0.10 & -0.43 \\
\hline & $\begin{array}{l}\text { Environmental } \\
\text { domain }\end{array}$ & -0.08 & -0.16 & -0.03 & 0.03 & 0.45 & 0.37 & 0.31 & 0.09 & 0.20 & -0.48 \\
\hline \multirow[t]{6}{*}{$\begin{array}{l}\text { Men }(N= \\
33)\end{array}$} & $\begin{array}{l}\text { Overall QOL } \\
\text { [score] }\end{array}$ & 0.14 & -0.14 & -0.05 & -0.04 & 0.21 & 0.13 & 0.42 & 0.23 & 0.11 & -0.12 \\
\hline & $\begin{array}{l}\text { General health } \\
\text { [score] }\end{array}$ & -0.05 & -0.11 & 0.01 & -0.01 & 0.21 & 0.13 & 0.26 & 0.07 & 0.14 & 0.09 \\
\hline & $\begin{array}{l}\text { Physical } \\
\text { domain }\end{array}$ & 0.06 & -0.21 & 0.04 & 0.09 & 0.48 & 0.37 & 0.47 & 0.46 & 0.06 & -0.25 \\
\hline & $\begin{array}{l}\text { Psychological } \\
\text { domain }\end{array}$ & -0.02 & -0.04 & 0.15 & 0.16 & 0.46 & 0.32 & 0.53 & 0.26 & -0.11 & -0.28 \\
\hline & Social domain & -0.08 & -0.15 & -0.03 & 0.03 & 0.15 & 0.28 & 0.15 & 0.19 & 0.17 & -0.02 \\
\hline & $\begin{array}{l}\text { Environmental } \\
\text { domain }\end{array}$ & -0.14 & -0.16 & 0.24 & 0.27 & 0.55 & 0.51 & 0.47 & 0.43 & -0.11 & -0.31 \\
\hline
\end{tabular}

Abbreviations: $N$ number of participants, $Q O L$ quality of life, $B M I$ body mass index

Notes: *values in bold indicate statistical significance $(p<0.05)$

women decreased more with age than in men. In the upper-body flexibility test (back scratch test), the women showed a better range of motion in the upper limb joints.

The last stage was a step-by-step regression analysis for the parametric results of the five performance tests: chair stand, arm curl, two-minute step test, back scratch test, and up and go test. These variables best explain the environmental, physical, and psychological QOL variables in both studied groups. The most dominant sphere of QOL of older adults in old age is the environmental sphere. This sense of security, health care, good material, living conditions, access to information, and realization of interests play a crucial role in assessing QOL.

Poland lacks specific standards for assessing the level of physical fitness of older people, particularly those over 80. Our study results can be very carefully related to the standards developed in the USA, in which 7183 people were tested, including 5048 women and 2135 men in day-care center residents [43]. In such a comparison, the Polish people aged 80 and above have been disadvantageous concerning American older adults. Particularly in the "two-minute step" and "up and go" tests, the results in both examined groups were significantly below the lower limit of the norm; only in the strength of the upper and lower body parts Polish older adults reached the lower limit for a comparable age group of US residents. On the other hand, in tests assessing upper and lower rim flexibility, the women surveyed achieved quite similar results to American standards, while the results of men, especially regarding lower body flexibility, were much lower.

Similar international research to ours has been conducted by Ignasiak et al. [44, 45], Grześkowiak et al. [46], and Katan et al. [47] in women and men, but younger age groups (50 to 76 years). In these studies, the results were also much worse than in the American population. The differences in the results obtained in our study can be considered due to the low level of physical activity of Polis older adults, as pointed out by Bień [48] as early as 2001 . At that time, $80 \%$ of people over 75 years old did not need to participate in rehabilitation programs.

The results of our study correspond with the results of the POLSENIOR project; the percentage of women with good QOL is lower than men [49]. Men rated QOL better than women in physical, psychological, and environmental fields. The self-assessment of health in our study in both groups was satisfactory, similarly, in the study by Waszkiewicz et al. [50]. The percentage of people satisfied with their health was higher among people over 80 . Analyzing the QOL profile in the scope of individual 
Table 4 Between sex differences for comparisons of QOL domains and physical fitness parameters according to participants' age

\begin{tabular}{|c|c|c|c|c|c|c|c|c|c|}
\hline \multirow[t]{3}{*}{ Feature } & & \multicolumn{8}{|l|}{ Effect } \\
\hline & & \multicolumn{3}{|l|}{ b } & \multicolumn{5}{|c|}{ Age [years] } \\
\hline & & Param. & $\mathbf{t}$ & $\mathbf{p}^{*}$ & Param. & $\mathbf{t}$ & $\mathrm{p}^{*}$ & $\beta$ & SE $\beta$ \\
\hline \multirow[t]{15}{*}{ Women $(N=67)$} & Height $[\mathrm{cm}]$ & 134.1 & 6.03 & $<0.001$ & 0.287 & 1.07 & 0.288 & 0.137 & 0.128 \\
\hline & Body mass [kg] & 72.2 & 1.86 & 0.068 & -0.038 & -0.08 & 0.935 & -0.011 & 0.129 \\
\hline & BMI $\left[\mathrm{kg} / \mathrm{m}^{2}\right]$ & 35.64 & 2.38 & 0.020 & -0.096 & -0.53 & 0.595 & -0.069 & 0.129 \\
\hline & Chair stand [n] & 34.70 & 2.70 & 0.009 & -0.330 & -2.13 & 0.038 & -0.265 & 0.124 \\
\hline & Arm curl $[n]$ & 22.00 & 1.39 & 0.168 & -0.147 & -0.78 & 0.441 & -0.100 & 0.128 \\
\hline & Two-minute step test [n] & 191.17 & 2.80 & 0.007 & -1.979 & -2.40 & 0.019 & -0.296 & 0.123 \\
\hline & Sit and reach test $[\mathrm{cm}]$ & 68.54 & 1.62 & 0.110 & -0.886 & -1.74 & 0.087 & -0.219 & 0.126 \\
\hline & Back scratch test $[\mathrm{cm}]$ & 135.40 & 2.02 & 0.048 & -1.911 & -2.37 & 0.021 & -0.292 & 0.123 \\
\hline & Up and go [s] & -22.37 & -0.47 & 0.642 & 0.501 & 0.87 & 0.389 & 0.111 & 0.128 \\
\hline & Overall QOL [score] & 7.32 & 1.95 & 0.056 & -0.042 & -0.94 & 0.351 & -0.121 & 0.128 \\
\hline & General health [score] & 8.62 & 2.19 & 0.032 & -0.063 & -1.33 & 0.188 & -0.169 & 0.127 \\
\hline & Physical domain & 71.12 & 3.37 & 0.001 & -0.563 & -2.21 & 0.031 & -0.275 & 0.124 \\
\hline & Psychological domain & 65.34 & 3.90 & $<0.001$ & -0.512 & -2.53 & 0.014 & -0.311 & 0.123 \\
\hline & Social domain & 20.92 & 2.88 & 0.006 & -0.111 & -1.27 & 0.208 & -0.162 & 0.127 \\
\hline & Environmental domain & 44.02 & 2.39 & 0.020 & -0.154 & -0.70 & 0.490 & -0.089 & 0.129 \\
\hline \multirow[t]{15}{*}{ Men $(N=33)$} & Height $[\mathrm{cm}]$ & 207.9 & 10.03 & $<0.001$ & -0.456 & -1.83 & 0.078 & -0.327 & 0.179 \\
\hline & Body mass [kg] & 128.1 & 3.52 & 0.002 & -0.602 & -1.37 & 0.180 & -0.251 & 0.183 \\
\hline & BMI $\left[\mathrm{kg} / \mathrm{m}^{2}\right]$ & 31.44 & 2.53 & 0.017 & -0.053 & -0.36 & 0.724 & -0.067 & 0.189 \\
\hline & Chair stand [n] & 24.24 & 1.31 & 0.201 & -0.175 & -0.79 & 0.438 & -0.147 & 0.187 \\
\hline & Arm curl [n] & 21.28 & 1.11 & 0.278 & -0.096 & -0.41 & 0.683 & -0.078 & 0.188 \\
\hline & Two-minute step test [n] & 20.51 & 0.23 & 0.818 & 0.242 & 0.23 & 0.821 & 0.043 & 0.189 \\
\hline & Sit and reach test $[\mathrm{cm}]$ & 11.49 & 0.44 & 0.665 & -0.175 & -0.55 & 0.584 & -0.104 & 0.188 \\
\hline & Back scratch test $[\mathrm{cm}]$ & -32.74 & -0.36 & 0.724 & 0.068 & 0.06 & 0.952 & 0.012 & 0.189 \\
\hline & Up and go [s] & 39.19 & 2.28 & 0.030 & -0.329 & -1.59 & 0.122 & -0.289 & 0.181 \\
\hline & Overall QOL [score] & 0.41 & 0.11 & 0.912 & 0.044 & 1.00 & 0.327 & 0.185 & 0.186 \\
\hline & General health [score] & 4.87 & 1.55 & 0.133 & -0.013 & -0.33 & 0.743 & -0.062 & 0.189 \\
\hline & Physical domain & 20.76 & 1.04 & 0.309 & 0.082 & 0.34 & 0.735 & 0.064 & 0.189 \\
\hline & Psychological domain & 38.76 & 2.34 & 0.027 & -0.169 & -0.85 & 0.405 & -0.158 & 0.187 \\
\hline & Social domain & 22.09 & 2.62 & 0.014 & -0.124 & -1.22 & 0.232 & -0.225 & 0.184 \\
\hline & Environmental domain & 62.43 & 3.42 & 0.002 & -0.345 & -1.57 & 0.127 & -0.285 & 0.181 \\
\hline
\end{tabular}

Abbreviations: BMI body mass index, QOL quality of life, $b$ regression coefficient, SE standard error, $t \mathrm{t}$-quantile, $p$ statistical significance, $\beta$ standardized regression coefficient

Notes: *values in bold indicate statistical significance $(p<0.05)$

Required Sample Size: N1 $=$ N2 $=26$

domains of the WHOQOL-BREF questionnaire, the highest scores were obtained in the group of men in the environmental and psychological spheres, in women in the environmental and social relations. Chruściel et al. [51] showed that living with older adults' relatives may be expected to be favorable for older adults because it translates into better physical, psychological and social domains. Also, loneliness, which frequently accompanies old age, leads to the deterioration of the QOL [51-53].

Polish cross-sectional study by Puciato et al. [27] conducted among over 1000 participants with the use of
WHOQOL-BREF showed that the overall QOL, the perceived health status, and the QOL in the physical, psychological, social, and environmental domains were significantly better in people with higher levels of physical activity assessed with the use of the International Physical Activity Questionnaire Short Version (IPAQ$\mathrm{SF})$. The highest mean indicators of overall QOL perceived health status and QOL in the physical, psychological, social, and environmental domains were shown in the older adults with the highest physical activity, which corresponded to our results. 
Table 5 Regression analysis of particular QOL domains according to physical fitness parameters among women

\begin{tabular}{|c|c|c|c|c|c|c|c|}
\hline Effect & & b & SE b & $t$ & $\mathrm{p}^{*}$ & $\beta$ & SE $\beta$ \\
\hline \multirow[t]{6}{*}{ Physical domain } & $b$ & 2.508 & 0.204 & 12.31 & $<0.001$ & & \\
\hline & Chair stand [n] & 0.132 & 0.025 & 5.19 & $<0.001$ & 0.544 & 0.105 \\
\hline & Arm curl [n] & & & & & & \\
\hline & Two-minute step test [n] & & & & & & \\
\hline & Back scratch test $[\mathrm{cm}]$ & & & & & & \\
\hline & Up and go [s] & & & & & & \\
\hline \multirow[t]{6}{*}{ Psychological domain } & b & 2.845 & 0.187 & 15.17 & $<0.001$ & & \\
\hline & Chair stand $[\mathrm{n}]$ & 0.131 & 0.023 & 5.62 & $<0.001$ & 0.575 & 0.102 \\
\hline & Arm curl [n] & & & & & & \\
\hline & Two-minute step test [n] & & & & & & \\
\hline & Back scratch test $[\mathrm{cm}]$ & & & & & & \\
\hline & Up and go [s] & & & & & & \\
\hline \multirow[t]{6}{*}{ Social domain } & $b$ & 3.296 & 0.168 & 19.67 & $<0.001$ & & \\
\hline & Chair stand [n] & 0.082 & 0.021 & 3.92 & 0.0002 & 0.440 & 0.112 \\
\hline & Arm curl [n] & & & & & & \\
\hline & Two-minute step test [n] & & & & & & \\
\hline & Back scratch test $[\mathrm{cm}]$ & & & & & & \\
\hline & Up and go [s] & & & & & & \\
\hline \multirow[t]{6}{*}{ Environmental domain } & $b$ & 3.780 & 0.245 & 15.44 & $<0.001$ & & \\
\hline & Chair stand [n] & & & & & & \\
\hline & Arm curl [n] & 0.044 & 0.018 & 2.49 & 0.0152 & 0.288 & 0.115 \\
\hline & Two-minute step test [n] & & & & & & \\
\hline & Back scratch test $[\mathrm{cm}]$ & & & & & & \\
\hline & Up and go [s] & -0.016 & 0.005 & -2.99 & 0.0039 & -0.346 & 0.115 \\
\hline
\end{tabular}

Abbreviations: $b$ regression coefficient, SE standard error, $t \mathrm{t}$-quantile, $p$ statistical significance, $\beta$ standardized regression coefficient Notes: *values in bold indicate statistical significance $(p<0.05)$; required sample size: $\mathrm{N} 1=\mathrm{N} 2=25$

Also, Nawrocka et al. [42] demonstrated that physical activity level is significantly associated with the social relationships domain of QOL. The researchers identified the differences in functional fitness (Senior Fitness Test and hand-grip strength) and QOL (WHOQOL-BREF) among women over 60 years of age depending on their level of objectively measured physical activity according to the Global Recommendations on Physical Activity for health. It was demonstrated a significant association between the upper body strength, dynamic balance, and social domains of QOL.

Umiastowska and Kupczyk [41] examined factors differentiating the level of functional fitness of older adults $(n=509)$ assessed with FFFT, and they confirm a higher level of functional fitness among active older adults, both women, and men in comparison with the American standards. According to the age, it was observed that both Polish women and men achieved moderate results, exceeding the upper limit of the range in American standards for the following tests: arm curl, chair sit-andreach, and 8-ft up and go. In the back scratch test, Polish seniors scored better. In the chair stand and two-minute step tests, the mean scores of the Polish respondents reached the upper limit of the range of standards in American studies.

Ihász et al. [54] aimed to assess the relationship between self-reported HRQOL and physical fitness (FFFT) in community-dwelling older females, including anthropometric parameters and body composition variables. The findings of this cross-sectional study of physical fitness and self-assessment of QOL in the group of older women showed that levels of physical fitness reflecting aerobic ability and muscle strength were significantly lower in the oldest group compared to the younger ones. The relationship between physical fitness and QOL was moderately and positively associated with physical functioning, as well as role limitations caused by physical and vitality problems. The authors call for 
Table 6 Regression analysis of particular QOL domains according to physical fitness parameters among men

\begin{tabular}{|c|c|c|c|c|c|c|c|}
\hline Effect & & b & SE b & $\mathbf{t}$ & $\mathrm{p}^{*}$ & $\beta$ & SE $\beta$ \\
\hline \multirow[t]{6}{*}{ Physical domain } & $b$ & 3.315 & 0.229 & 14.49 & $<0.001$ & & \\
\hline & Chair stand [n] & & & & & & \\
\hline & Arm curl [n] & & & & & & \\
\hline & Two-minute step test [n] & 0.015 & 0.005 & 2.97 & 0.0058 & 0.477 & 0.160 \\
\hline & Back scratch test $[\mathrm{cm}]$ & & & & & & \\
\hline & Up and go [s] & & & & & & \\
\hline \multirow[t]{6}{*}{ Psychological domain } & b & 3.534 & 0.220 & 16.06 & $<0.001$ & & \\
\hline & Chair stand $[\mathrm{n}]$ & & & & & & \\
\hline & Arm curl [n] & & & & & & \\
\hline & Two-minute step test [n] & 0.015 & 0.005 & 3.02 & 0.0051 & 0.483 & 0.160 \\
\hline & Back scratch test $[\mathrm{cm}]$ & & & & & & \\
\hline & Up and go [s] & & & & & & \\
\hline \multirow[t]{6}{*}{ Social domain } & b & 3.969 & 0.112 & 35.32 & $<0.001$ & & \\
\hline & Chair stand [n] & & & & & & \\
\hline & Arm curl [n] & & & & & & \\
\hline & Two-minute step test [n] & & & & & & \\
\hline & Back scratch test $[\mathrm{cm}]$ & & & & & & \\
\hline & Up and go [s] & & & & & & \\
\hline \multirow[t]{6}{*}{ Environmental domain } & $b$ & 3.507 & 0.217 & 16.17 & $<0.001$ & & \\
\hline & Chair stand [n] & 0.071 & 0.020 & 3.46 & 0.0017 & 0.534 & 0.154 \\
\hline & Arm curl [n] & & & & & & \\
\hline & Two-minute step test [n] & & & & & & \\
\hline & Back scratch test $[\mathrm{cm}]$ & & & & & & \\
\hline & Up and go [s] & & & & & & \\
\hline
\end{tabular}

Abbreviations: $b$ regression coefficient, $S E$ standard error, $t$ t-quantile, $p$ statistical significance, $\beta$ standardized regression coefficient Notes: *values in bold indicate statistical significance $(p<0.05)$; required sample size: $\mathrm{N} 1=\mathrm{N} 2=25$

action in research to determine the impact of an active lifestyle on functional performance (balance and resistance exercises) and increase the number of components to be assessed and conduct a longitudinal and interventional study.

Many researchers indicate age as one of the crucial predictors affecting QOL $[55,56]$. In our study, in the women's group, age proved to be an essential factor affecting the assessment in all domains and selfassessment of health. The analysis unequivocally showed negative relationships, namely, the older the woman, the lower the QOL score. The men's group showed significant negative relationships between age and the psychological, social, and environmental spheres.

The evidence provided by Vagetti et al. [57] in their systematic review pointed out that the promotion of physical activity in the elderly population can have an impact exceeding the functional abilities and mental health because it involves a positive perception of the overall QOL. However, these findings also showed that physical activity might not be related to certain areas of
QOL (e.g., sensory performance); therefore, further studies are needed.

To summarize, due to numerous factors influencing the QOL of people aged 80 and over, its assessment is problematic. Systematic physical activity allowing to maintain physical performance, independence, and autonomy, are factors influencing the enhancement of QOL, as demonstrated by the literature on the subject and the present study results. However, in QOL studies of elderly people, it should be remembered that the physical and mental health of these people is the result of life experience and the current situation, which is determined by many psychosocial and spiritual factors.

\section{Study limitations}

This study has some potential methodological limitations. First of all, the cross-sectional protocol of this study makes it difficult to provide a clear interpretation of the relationship between the physical fitness parameters and QOL of the study participants. Secondly, the surveyed population is limited to quite a small number 


\section{Appendix}

Table 7 English translation of an original survey questionnaire designed by the authors including 40 questions in terms of biometric data, anthropometric characteristics, family and environmental situation, nutritional and lifestyle behaviors

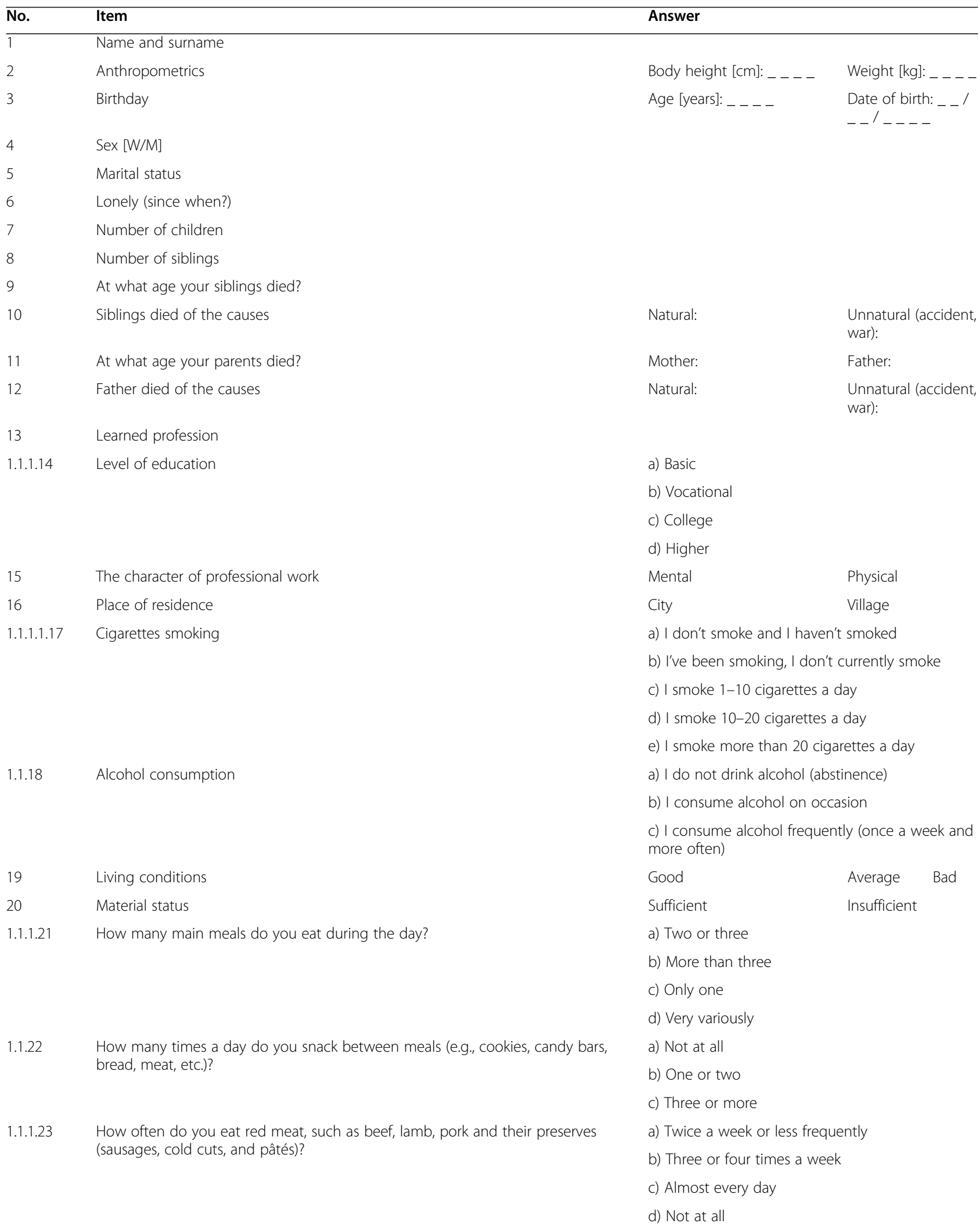


Table 7 English translation of an original survey questionnaire designed by the authors including 40 questions in terms of biometric data, anthropometric characteristics, family and environmental situation, nutritional and lifestyle behaviors (Continued)

\begin{tabular}{|c|c|c|}
\hline No. & Item & Answer \\
\hline \multirow[t]{3}{*}{$\overline{1.1 .24}$} & \multirow[t]{3}{*}{ How often do you eat fresh fruit and vegetables (raw or cooked)? } & a) Twice a day and more often \\
\hline & & b) Almost every day \\
\hline & & c) Less than four times a week \\
\hline \multirow[t]{4}{*}{ 1.1.1.25 } & \multirow{4}{*}{$\begin{array}{l}\text { How often do you eat products such as brown, unshelled rice, thick groats, whole } \\
\text { meal bread, oatmeal? }\end{array}$} & a) At least once a day \\
\hline & & b) 3-6 times a week \\
\hline & & c) Less than three times a week \\
\hline & & d) Not at all \\
\hline \multirow[t]{4}{*}{ 1.1.1.26 } & \multirow[t]{4}{*}{ How many times a week do you eat fried food? } & a) Almost every day \\
\hline & & b) About three times a week \\
\hline & & c) Once a week or less frequently \\
\hline & & d) Not at all \\
\hline \multirow[t]{3}{*}{ 1.1.27 } & \multirow{3}{*}{$\begin{array}{l}\text { Do you eat fast-food (hot dogs, hamburgers, pizzas), salty and fatty snacks (chips, } \\
\text { sausages, crackers)? }\end{array}$} & a) Yes \\
\hline & & b) Sometimes \\
\hline & & c) Not at all \\
\hline \multirow[t]{3}{*}{ 1.1.28 } & \multirow[t]{3}{*}{ How often do you eat fish? } & a) Twice a week or more often \\
\hline & & b) Less than once a week \\
\hline & & c) Not at all \\
\hline \multirow[t]{4}{*}{ 1.1.1.29 } & \multirow[t]{4}{*}{ How often do you eat butter, drink whole fat milk or use cream? } & a) 3-4 times a day \\
\hline & & b) Once a day \\
\hline & & c) Several times a week or less frequently \\
\hline & & d) I avoid fatty additives \\
\hline \multirow[t]{4}{*}{ 1.1.1.30 } & \multirow[t]{4}{*}{ How many cups (glasses, mugs) of coffee do you drink a day? } & a) Two or less \\
\hline & & b) Three-four \\
\hline & & c) More than five \\
\hline & & d) Not at all \\
\hline \multirow[t]{4}{*}{ 1.1.1.31 } & \multirow[t]{4}{*}{ How many glasses (cups) of sweetened drinks do you drink a day? } & a) Two or less \\
\hline & & b) Three-four \\
\hline & & c) More than five \\
\hline & & d) Not at all \\
\hline \multirow[t]{4}{*}{ 1.1.1.32 } & \multirow[t]{4}{*}{ Do you often eat sweets (e.g., chocolate, candies, cakes)? } & a) Every day or almost every day \\
\hline & & b) About three times a week \\
\hline & & c) Once a week or less frequently \\
\hline & & d) Not at all \\
\hline \multirow[t]{3}{*}{1.1 .33} & \multirow[t]{3}{*}{ How many liquids do you drink a day (water, tea, soup)? } & a) About 3-6 glasses \\
\hline & & b) About 6-10 glasses \\
\hline & & c) More than 10 glasses \\
\hline \multirow[t]{3}{*}{1.1 .34} & \multirow[t]{3}{*}{ Do you sometimes eat late at night? } & a) Yes \\
\hline & & b) Sometimes \\
\hline & & c) $\mathrm{No}$ \\
\hline \multirow[t]{3}{*}{1.1 .35} & \multirow[t]{3}{*}{ Do you sometimes eat in a hurry (e.g., breakfast)? } & a) Yes \\
\hline & & b) Sometimes \\
\hline & & c) No \\
\hline 1.1.1.1.36 & How often do you check your weight? & a) Everyday \\
\hline
\end{tabular}


Table 7 English translation of an original survey questionnaire designed by the authors including 40 questions in terms of biometric data, anthropometric characteristics, family and environmental situation, nutritional and lifestyle behaviors (Continued)

\begin{tabular}{|c|c|c|}
\hline No. & Item & Answer \\
\hline & & b) Once a week \\
\hline & & c) Once a month \\
\hline & & d) Once every six months \\
\hline & & e) Not at all \\
\hline \multirow[t]{7}{*}{ 1.1.1.1.1.1.37 } & \multirow[t]{7}{*}{ What kind of products did you eat as a child? } & a) Meat \\
\hline & & b) Milk, butter, cream \\
\hline & & c) Breads \\
\hline & & d) Sweets \\
\hline & & e) Fruit \\
\hline & & f) Vegetables \\
\hline & & g) Fish \\
\hline \multirow[t]{6}{*}{ 1.1.1.1.1.1.38 } & \multirow{6}{*}{$\begin{array}{l}\text { Assign the following products to the individual floors of the health pyramid for } \\
\text { seniors: }\end{array}$} & a) Meat, cold cuts, dairy products \\
\hline & & b) Liquid, water, tea \\
\hline & & c) Carbohydrates (bread, cereals, rice) \\
\hline & & d) Fats, sweets, red meat \\
\hline & & e) Vegetables and sweets \\
\hline & & f) I don't know what it is \\
\hline 39 & What diseases do you suffer from? & \\
\hline \multirow[t]{4}{*}{ 1.1.1.40 } & \multirow[t]{4}{*}{ Fill the values of the following tests: } & a) Glucose level: _ _ _ \\
\hline & & b) Total cholesterol level: __ _- \\
\hline & & c) Blood pressure: $\_-{ }_{-} /$ \\
\hline & & d) Hypertension (yes/no): _ _ \\
\hline
\end{tabular}

of participants $(n=100)$ living in the south-western regions of Poland, which makes it impossible to generalize the results for the entire population of Polish older adults. And the last but not least, the different group sizes concerning men and women were recruited in the present study. There is a need to conduct a prospective study on this important subject, including multicenter research. Moreover, further studies should also consider including more study outcomes such as anthropometric parameters (e.g., waist, arm, tight, and calf circumferences, waist-to-height ratio, arm fat area, skinfold thickness, and muscle thickness) and body composition parameters (fat percent, fat-free mass, visceral fat, bone mass, total body water, basal metabolic rate, and metabolic age). Also, it should be noticed that the age range is $80-83$ and, thus, the results are not directly comparable to the studies where the participants we aged below 80 years old.

\section{Research directions}

Undoubtedly, physical fitness is associated with QOL in older adults. Our findings emphasize the importance of maintaining good physical condition and its relationship with QOL levels. Because of the slightly lower physical fitness, women are exposed to reduced QOL. Therefore, further research should consider developing global 
standards and strategies for activity programs aimed at maintaining good physical condition, which could effectively improve overall QOL, especially in women. It seems necessary to promote the beneficial effects of health training on the organism through promotion and information programs for people coming into the autumn of life. People over 50 years of age should be aware that fitness and age-appropriate physical activity is the best way to maintain health, longevity, and well-being and encourage older adults to participate in physical activity programs [58]. Such programs, e.g., after 1 year of follow-up, appear to increase daily physical activity levels in older adults $[59,60]$.

\section{Conclusions}

Community-dwelling older adults aged $80-93$ years in Poland present a good level of QOL, and the higher score was obtained in men. Also, men presented better physical fitness, showed a higher level of independence in daily activities, and assessed better their own QOL than women. Physical, psychological, and environmental domains are important in the QOL assessment of older adults. The positive assessment of older men and women in terms of QOL is associated with the level of their physical fitness, in particular: mobility endurance, upper and lower body strength, balance, coordination, and speed.

\section{Abbreviations}

HRQOL: Health-related quality of life; QOL: Quality of life; WHOQOLBREF: World health organization QOL, short form; FFFT: Fullerton functional fitness test; WHO: World health organization; STROBE: Strengthening the Reporting of Observational studies in epidemiology guidelines

\section{Acknowledgments}

There were no other contributors to the article than the authors as well as there was no writing assistance regarding our paper. We would like to thank all the study subjects.

\section{Authors' contributions}

EL was responsible for conception and design of the present study; collected; and analysed the data; wrote the manuscript. GŻ was responsible for conception and design of the present study; analysed the data; wrote the manuscript. ER and AR collected the data. AŻ designed the present study. AKa collected the data. AKo collected and analysed the data; and wrote the manuscript. All authors have made substantial contributions to the design of the study and the manuscript. All authors revised the manuscript critically for important intellectual content. All authors have read and approved the manuscript. All authors agreed to be accountable for all aspects of the work in ensuring that questions related to the accuracy or integrity of any part of the work are appropriately investigated and resolved.

\section{Funding}

None.

\section{Availability of data and materials}

The datasets used and/or analyzed during the current study are available from the corresponding author on reasonable request.

\section{Declarations}

\section{Ethics approval and consent to participate}

The study protocol was approved by the Bioethics Committee of the Opole Medical School, Poland (permission no. 3/2015). All participants gave written informed consent after a thorough explanation of the procedures involved. The study was carried out in accordance with the guidelines of the Declaration of Helsinki and Good Clinical Practice. All participants gave their informed consent to participate in this study.

\section{Consent for publication}

Not applicable.

\section{Competing interests}

The authors declare that they have no competing interests.

\section{Author details}

${ }^{1}$ Institute of Health Sciences, University of Opole, Opole, Poland.

2Department of Biostructure, University School of Physical Education, Wroclaw, Poland. ${ }^{3}$ Department of Clinical Psychology and Health, University of Wroclaw, Wroclaw, Poland. ${ }^{4}$ Department of Physiotherapy, Krapkowice Health Centre, Krapkowice, Poland. ${ }^{5}$ Laboratory of Ergonomics and Biomedical Monitoring, Wroclaw Medical University, Grunwaldzka 2, 50-355, Wroclaw, Poland.

Received: 7 October 2020 Accepted: 19 August 2021

Published online: 09 September 2021

\section{References}

1. Kingston A, Comas-Herrera A, Jagger C. MODEM project. Forecasting the care needs of the older population in England over the next 20 years: estimates from the population ageing and care simulation (PACSim) modelling study. Lancet Public Health. 2018;3(9):e447-55. https://doi.org/1 0.1016/S2468-2667(18)30118-X.

2. Cheng X, Yang Y, Schwebel DC, Liu Z, Li L, Cheng P, et al. Population ageing and mortality during 1990-2017: A global decomposition analysis. PLoS Med. 2020;17(6):e1003138. https://doi.org/10.1371/journal.pmed.1 003138

3. Eurostat. Population Structure and Ageing. Luxembourg City, Luxembourg: Eurostat; 2019. https://ec.europa.eu/eurostat/statistics-explained/index.php/ Population_structure_and_ageing.

4. Leszko M, Zając-Lamparska L, Trempala J. Aging in Poland. Gerontologist. 2015;55(5):707-15. https://doi.org/10.1093/geront/gnu171.

5. Derejczyk J, Bień B, Kokoszka-Paszkot J, Szczygieł J. Gerontology and geriatrics in Poland against Europe - is it necessary to invest in? Pol Gerontol. 2008;16:149-59.

6. Liotta G, Canhao H, Cenko F, Cutini R, Vellone E, Illario M, et al. Active Ageing in Europe: Adding Healthy Life to Years. Front Med (Lausanne). 2018:55(5):707-15. https://doi.org/10.3389/fmed.2018.00123.

7. World Health Organization. Global action plan on physical activity 20182030: more active people for a healthier world. Geneva: World Health Organization; 2018. https://apps.who.int/iris/bitstream/handle/10665/272 722/9789241514187-eng.pdf.

8. American College of Sports Medicine, Chodzko-Zajko WJ, Proctor DN, Fiatarone Singh MA, Minson CT, Nigg CR, et al. American College of Sports Medicine position stand. Exercise and physical activity for older adults. Med Sci Sports Exerc. 2009;41:1510-30

9. Vanhees L, Lefevre J, Philippaerts R, Martens M, Huygens W, Troosters T, et al. How to assess physical activity? How to assess physical fitness? Eur J Cardiovasc Prev Rehabil. 2005;12(2):102-14. https://doi.org/10.1097/01.hjr. $0000161551.73095 .9 c$.

10. Bouaziz W, Lang PO, Schmitt E, Kaltenbach G, Geny B, Vogel T. Health benefits of multicomponent training programmes in seniors: a systematic review. Int J Clin Pract. 2016;70(7):520-36. https://doi.org/10.1111/ijcp.12822.

11. Bouaziz W, Vogel T, Schmitt E, Kaltenbach G, Geny B, Lang PO. Health benefits of aerobic training programs in adults aged 70 and over: a systematic review. Arch Gerontol Geriatr. 2017;69:110-27. https://doi.org/1 0.1016/.archger.2016.10.012

12. Hillman $\mathrm{CH}$, Erickson $\mathrm{Kl}$, Kramer AF. Be smart, exercise your heart: exercise effects on brain and cognition. Nat Rev Neurosci. 2008:9(1):58-65. https:// doi.org/10.1038/nrn2298. 
13. Booth FW, Roberts CK, Laye MJ. Lack of exercise is a major cause of chronic diseases. Compr Physiol. 2012;2(2):1143-211. https://doi.org/10.1002/cphy. c110025.

14. Lavie CJ, Ozemek C, Carbone S, Katzmarzyk PT, Blair SN. Sedentary behavior, exercise, and cardiovascular health. Circ Res. 2019;124(5):799-815. https:// doi.org/10.1161/CIRCRESAHA.118.312669.

15. Gopinath B, Kifley A, Flood VM, Mitchell P. Physical activity as a determinant of successful aging over ten years. Sci Rep. 2018;8(1):10522. https://doi.org/1 0.1038/s41598-018-28526-3.

16. Rebelo-Marques A, De Sousa LA, Andrade R, Ribeiro CF, Mota-Pinto A, Carrilho F, et al. Aging Hallmarks: The Benefits of Physical Exercise. Front Endocrinol (Lausanne). 2018;25(9):258. https://doi.org/10.3389/fendo.2018. 00258.

17. Buford TW, Anton SD, Clark DJ, Higgins TJ, Cooke MB. Optimizing the benefits of exercise on physical function in older adults. PM R. 2014;6(6): 528-43. https://doi.org/10.1016/j.pmrj.2013.11.009.

18. Rivera-Torres S, Fahey TD, Rivera MA. Adherence to exercise programs in older adults: informative report. Gerontol Geriatr Med. 2019;5: 233372141882360. https://doi.org/10.1177/2333721418823604.

19. Carvalho A, Rea IM, Parimon T, Cusack BJ. Physical activity and cognitive function in individuals over 60 years of age: a systematic review. Clin Interv Aging. 2014;9:661-82. https://doi.org/10.2147/CIA.S55520.

20. Gheysen F, Poppe L, DeSmet A, Swinnen S, Cardon G, De Bourdeaudhuij I, et al. Physical activity to improve cognition in older adults: can physical activity programs enriched with cognitive challenges enhance the effects? A systematic review and meta-analysis. Int J Behav Nutr Phys Act. 2018; 15(1):63. https://doi.org/10.1186/s12966-018-0697-x.

21. Fielding RA, Guralnik JM, King AC, Pahor M, McDermott MM, Tudor-Locke C, et al. Dose of physical activity, physical functioning and disability risk in mobility-limited older adults: results from the LIFE study randomized trial. PLoS One. 2017;12(8):e0182155. https://doi.org/10.1371/journal.pone.0182155.

22. Sink KM, Espeland MA, Castro CM, Church T, Cohen R, Dodson JA, et al. Effect of a 24-month physical activity intervention vs health education on cognitive outcomes in sedentary older adults: the LIFE randomized trial. JAMA. 2015;314(8):781-90. https://doi.org/10.1001/jama.2015.9617.

23. Langhammer B, Bergland A, Rydwik E. The importance of physical activity exercise among older people. Biomed Res Int. 2018;2018:1-3. https://doi. org/10.1155/2018/7856823.

24. McPhee JS, French DP, Jackson D, Nazroo J, Pendleton N, Degens H. Physical activity in older age: perspectives for healthy ageing and frailty. Biogerontology. 2016;17(3):567-80. https://doi.org/10.1007/s10522-016-9641-0.

25. Tishukaj F, Shalaj I, Gjaka M, Ademi B, Ahmetxhekaj R, Bachl N, et al. Physical fitness and anthropometric characteristics among adolescents living in urban or rural areas of Kosovo. BMC Public Health. 2017;17(1):711. https:// doi.org/10.1186/s12889-017-4727-4.

26. Daimiel L, Martínez-González MA, Corella D, Salas-Salvadó J, Schröder H, Vioque J, et al. Physical fitness and physical activity association with cognitive function and quality of life: baseline cross-sectional analysis of the PREDIMED-plus trial. Sci Rep. 2020;10(1):3472. https://doi.org/10.1038/s41 598-020-59458-6.

27. Puciato D, Borysiuk Z, Rozpara M. Quality of life and physical activity in an older working-age population. Clin Interv Aging. 2017;12:1627-34. https:// doi.org/10.2147/CIA.S144045

28. Oh S-H, Kim D-K, Lee S-U, Jung SH, Lee SY. Association between exercise type and quality of life in a community-dwelling older people: a crosssectional study. PLoS One. 2017;12(12):e0188335. https://doi.org/10.1371/ journal.pone.0188335.

29. Burton E, Farrier K, Galvin R, Johnson S, Horgan NF, Warters A, et al. Physical activity programs for older people in the community receiving home care services: systematic review and meta-analysis. Clin Interv Aging. 2019;14: 1045-64. https://doi.org/10.2147/CIA.S205019.

30. Morgan GS, Willmott M, Ben-Shlomo Y, Haase AM, Campbell RM. A life fulfilled: positively influencing physical activity in older adults - a systematic review and meta-ethnography. BMC Public Health. 2019;19(1):362. https:// doi.org/10.1186/s12889-019-6624-5.

31. Ćwirlej-Sozańska A, Wilmowska-Pietruszyńska A, Sozański B. Validation of the polish version of the World Health Organization disability assessment schedule (WHODAS 2.0) in an elderly population (60-70 years old). Int J Occup Saf Ergon. 2018;24(3):386-94. https://doi.org/10.1080/10803548.201 7.1316596.
32. Ćwirlej-Sozańska A, Wiśniowska-Szurlej A, Wilmowska-Pietruszyńska A, Sozański B. Determinants of ADL and IADL disability in older adults in southeastern Poland. BMC Geriatr. 2019;19(1):297. https://doi.org/10.1186/ s12877-019-1319-4.

33. Ćwirlej-Sozańska A, Wilmowska-Pietruszyńska A, Wiśniowska-Szurlej A, Sozański B. Analysis of health, functioning and disability of rural inhabitants aged 60-80 living in South-Eastern Poland - a cross sectional study. Ann Agric Environ Med. 2017;25(3):388-94. https://doi.org/10.5604/12321966.1235175.

34. Skevington SM, Lotfy M, O'Connell KA, WHOQOL Group. The World Health Organization's WHOQOL-BREF quality of life assessment: psychometric properties and results of the international field trial A report from the WHOQOL group. Qual Life Res. 2004;13:299-310.

35. Wong FY, Yang L, Yuen JWM, Chang KKP, Wong FKY. Assessing quality of life using WHOQOL-BREF: a cross-sectional study on the association between quality of life and neighborhood environmental satisfaction, and the mediating effect of health-related behaviors. BMC Public Health. 2018; 18(1):1113. https://doi.org/10.1186/s12889-018-5942-3.

36. Suárez L, Tay B, Abdullah F. Psychometric properties of the World Health Organization WHOQOL-BREF quality of life assessment in Singapore. Qual Life Res. 2018;27(11):2945-52. https://doi.org/10.1007/s11136-018-1947-8.

37. Jaracz K, Kalfoss M, Górna K, Baczyk G. Quality of life in polish respondents: psychometric properties of the polish WHOQOL-Bref. Scand J Caring Sci. 2006;20(3):251-60. https://doi.org/10.1111/j.1471-6712.2006.00401.x.

38. Rikli RE, Jones CJ. Assessing physical performance in independent older adults: issues and guidelines. J Aging Phys Activ. 1997;5(3):244-61. https:// doi.org/10.1123/japa.5.3.244.

39. Rikli RE, Jones CJ. Development and validation of criterion-referenced clinically relevant fitness standards for maintaining physical independence in later years. Gerontologist. 2013;53(2):255-67. https://doi.org/10.1093/ geront/gns071.

40. Ignasiak Z, Sebastjan A, Sławińska T, Skrzek A, Czarny W, Król P, et al. Functional fitness normative values for elderly polish population. BMC Geriatr. 2020;20(1):384. https://doi.org/10.1186/s12877-020-01787-2.

41. Umiastowska D, Kupczyk J. Factors differentiating the level of functional fitness in polish seniors. Int J Environ Res Public Health. 2020;17(5). https:// doi.org/10.3390/ijerph17051699.

42. Nawrocka A, Polechoński J, Garbaciak W, Mynarski W. Functional fitness and quality of life among women over 60 years of age depending on their level of objectively measured physical activity. Int J Environ Res Public Health 2019;16(6). https://doi.org/10.3390/ijerph16060972.

43. Rikli RE, Jones CJ. Functional fitness normative scores for communityresiding older adults, ages 60-94. J Aging Phys Activ. 1999;7(2):162-81. https://doi.org/10.1123/japa.7.2.162

44. Ignasiak Z, Domaradzki J, Kaczorowska A, Katan A. Poziom sprawności ruchowej mężczyzn w wieku 60-79 lat. J Kinesiol Exerc Sci. 2009;19:17-24.

45. Ignasiak Z, Kaczorowska A, Katan A, Domaradzki J. Evaluation of fitness of elderly women by means of Fullerton test. Physiotherapy. 2009;17:48-52.

46. Grześkowiak J, Wieliński W. Comparison of selected physical activity parameters of over 65-year-old women researched with the method of the Fullerton functional fitness test with population research leaded in the Usa by Rikli and Jones. J Kinesiol Exerc Sci. 2009;45:77-82.

47. Katan A, Kaczorowska A, Ignasiak Z. The physical fitness of women is assessed by a seniors' test in terms of sanatorium admission. J Kinesiol Exerc Sci. 2013;63:55-60

48. Bień B. Grand geriatric problems as a cause of disability in elderly people. Pol Gerontol. 2001;9:32-8.

49. Szybalska A, Broczek K, Puzianowska-Kuznicka M, Slusarczyk P, Chudek J, Skalska A, et al. Self-rated health and its association with all-cause mortality of older adults in Poland: the PolSenior project. Arch Gerontol Geriatr. 2018; 79:13-20. https://doi.org/10.1016/j.archger.2018.07.016.

50. Waszkiewicz L, Einhorn J, Połtyn-Zaradna K, Gaweł-Dżbrowska D, Grabowska B, Zatońska K. Quality of life of polish elderly people. In: Mossakowska M, editor. Medical, psychological, sociological and economic aspects of human ageing in Poland. Poznan: Termedia; 2012. p. 549-60.

51. Chruściel P, Szczekala KM, Derewiecki T, Jakubowska K, Nalepa D, Czekirda $M E$, et al. Differences in the quality of life dependent on family status of the elderly living in rural areas - a cross-sectional survey. Ann Agric Environ Med. 2018;25(3):532-8. https://doi.org/10.26444/aaem/93501.

52. Beridze G, Ayala A, Ribeiro O, Fernández-Mayoralas G, Rodríguez-Blázquez C, Rodríguez-Rodríguez $\mathrm{V}$, et al. Are loneliness and social isolation associated with quality of life in older adults? Insights from northern and southern 
Europe. Int J Environ Res Public Health. 2020;17(22). https://doi.org/10.3390/ ijerph17228637.

53. Gerino E, Rollè L, Sechi C, Brustia P. Loneliness, resilience, mental health, and quality of life in old age: a structural equation model. Front Psychol. 2017;8. https://doi.org/10.3389/fpsyg.2017.02003.

54. Ihász F, Schulteisz N, Finn KJ, Szabó K, Gangl J, Nagy D, et al. Associations between fitness levels and self-perceived health-related quality of life in community - dwelling for a group of older females. BMC Public Health. 2020;20(Suppl 1):1057. https://doi.org/10.1186/s12889-020-08473-3.

55. García EL, Banegas JR, Pérez-Regadera AG, Cabrera RH, Rodríguez-Artalejo F. Social network and health-related quality of life in older adults: a population-based study in Spain. Qual Life Res. 2005;14(2):511-20. https:// doi.org/10.1007/s11136-004-5329-z.

56. McBurney CR, Eagle KA, Kline-Rogers EM, Cooper JV, Mani OCM, Smith DE, et al. Health-related quality of life in patients 7 months after a myocardial infarction: factors affecting the short Form-12. Pharmacotherapy. 2002; 22(12):1616-22. https://doi.org/10.1592/phco.22.17.1616.34121.

57. Vagetti GC, Barbosa Filho VC, Moreira NB, de Oliveira V, Mazzardo O, de Campos W, et al. Association between physical activity and quality of life in the elderly: a systematic review, 2000-2012. Brazil J Psychiatry. 2014;36(1):7688. https://doi.org/10.1590/1516-4446-2012-0895.

58. Kelly ME, Loughrey D, Lawlor BA, Robertson IH, Walsh C, Brennan S. The impact of exercise on the cognitive functioning of healthy older adults: a systematic review and meta-analysis. Ageing Res Rev. 2014;16:12-31. https:// doi.org/10.1016/j.arr.2014.05.002.

59. Schröder H, Cárdenas-Fuentes G, Martínez-González MA, Corella D, Vioque J, Romaguera $\mathrm{D}$, et al. Effectiveness of the physical activity intervention program in the PREDIMED-plus study: a randomized controlled trial. Int Behav Nutr Phys Act. 2018;15(1):110. https://doi.org/10.1186/s12966-0180741-X.

60. Esain I, Gil SM, Bidaurrazaga-Letona I, Rodriguez-Larrad A. Effects of 3 months of detraining on functional fitness and quality of life in older adults who regularly exercise. Aging Clin Exp Res. 2019;31(4):503-10. https://doi. org/10.1007/s40520-018-0990-1.

\section{Publisher's Note}

Springer Nature remains neutral with regard to jurisdictional claims in published maps and institutional affiliations.

Ready to submit your research? Choose BMC and benefit from:

- fast, convenient online submission

- thorough peer review by experienced researchers in your field

- rapid publication on acceptance

- support for research data, including large and complex data types

- gold Open Access which fosters wider collaboration and increased citations

- maximum visibility for your research: over $100 \mathrm{M}$ website views per year

At $\mathrm{BMC}$, research is always in progress.

Learn more biomedcentral.com/submissions 